Joachim Boldt

Stephan Suttner

Christian Brosch

Andreas Lehmann

Kerstin Röhm

Andinet Mengistu

\section{Retraction Note: The influence of a balanced volume replacement concept on inflammation, endothelial activation, and kidney integrity in elderly cardiac surgery patients}

Published online: 21 May 2011

(C) Copyright jointly held by Springer and ESICM 2011

The online version of the original article can be found under doi:10.1007/s00134-008-1287-1.

J. Boldt ( $)$ S. Suttner - C. Brosch · A. Lehmann ·

K. Röhm · A. Mengistu

Department of Anesthesiology and Intensive Care Medicine,

Klinikum der Stadt Ludwigshafen,

Bremserstr. 79, 67063 Ludwigshafen, Germany

e-mail: BoldtJ@gmx.net

Fax: +621-503-3024

\section{Retraction Note: Intensive Care Med (2009)}

\section{5:462-470}

DOI 10.1007/s00134-008-1287-1

This article has been retracted as the IRB approval for the research was misrepresented. The investigating committee at Klinikum Ludwigshafen found the lack of IRB approval and this is unethical. It does not mean that the research results per se are fraudulent. The investigating committee is systematically assessing the veracity of the findings presented in Dr. Boldt's articles against patient and laboratory records. We will communicate to our readers any finding of data fabrication or misrepresentation identified by the investigating committee. 